\title{
Adsorption of Phenol from Aqueous Solutions by Carbon Nanomaterials of One and Two Dimensions: Kinetic and Equilibrium Studies
}

\author{
M. de la Luz-Asunción, ${ }^{1,2,3}$ V. Sánchez-Mendieta, ${ }^{1}$ A. L. Martínez-Hernández, ${ }^{2,3}$ \\ V. M. Castaño, ${ }^{2}$ and C. Velasco-Santos ${ }^{2,3}$ \\ ${ }^{1}$ Faculty of Chemistry, Autonomous University of the State of Mexico, Km. 12 de la Carretera Toluca-Atlacomulco, \\ San Cayetano, 50200 Toluca, MEX, Mexico \\ ${ }^{2}$ Center of Applied Physics and Advanced Technology, National Autonomous University of Mexico, Boulevard Juriquilla No. 3001, \\ Juriquilla, 76230 Santiago de Querétaro, QRO, Mexico \\ ${ }^{3}$ Division of Postgraduate Studies and Research, Technological Institute of Queretaro, Avenida Tecnológico s/n, \\ Esquina Gral. Mariano Escobedo, Colonia Centro Histórico, 76000 Santiago de Querétaro, QRO, Mexico
}

Correspondence should be addressed to C. Velasco-Santos; cylaura@gmail.com

Received 26 September 2015; Revised 28 November 2015; Accepted 29 November 2015

Academic Editor: Hassan Karimi-Maleh

Copyright (C) 2015 M. de la Luz-Asunción et al. This is an open access article distributed under the Creative Commons Attribution License, which permits unrestricted use, distribution, and reproduction in any medium, provided the original work is properly cited.

Carbon nanomaterials have a great potential in environmental studies; they are considered as superior adsorbents of pollutants due to their physical and chemical properties. Functionalization and dimension play an important role in many functions of these nanomaterials including adsorption. In this research, adsorption process was achieved with one-dimension nanomaterials: single walled and multiwalled carbon nanotubes were used as received and after oxidation treatment also two-dimensional nanomaterials were used: graphene oxide and reduced graphene oxide. Carbon nanotubes were modified by hydrogen peroxide under microwave irradiation. The reduction of graphene oxide was achieved by using ascorbic acid. $R^{2}$ values obtained with the pseudo-secondorder model are higher than 0.99 . The results demonstrate that Freundlich isotherm provides the best fit for the equilibrium data $\left(R^{2}>0.94\right)$. $R_{L}$ values are between 0 and 1; this represents favorable adsorption between carbon nanomaterials and phenol. The adsorption process occurs by $\pi-\pi$ interactions and hydrogen bonding and not by electrostatic interactions. The results indicate that the adsorption of phenol on carbon nanomaterials depends on the adsorbents' surface area, and it is negatively influenced by the presence of oxygenated groups.

In memoriam Dr. Adolfo M. Espíndola-González (1977-2014)

\section{Introduction}

The problem of water pollution is a big challenge in our time. Due to rapid population growth, water demand is higher every day [1]. The discharge of wastewater containing large amounts of organic contaminants represents a serious risk to the general population [2]. Wastewater containing organic contaminants such as phenolic compounds implies serious discharge problems, due to their poor biodegradability, high toxicity, and possible accumulation in the environment.
Phenols are introduced into surface water from industrial effluents, such as those from plastic, leather, paint, rubber, pharmaceuticals, petrochemicals, and pesticides, among others [3-5]. It is a fact that phenol and its derivatives found in natural water sources represent a serious risk to human health and water quality [6]. Phenolic compounds represent a serious danger because of their high toxicity and carcinogenicity even at low concentrations. Environmental Protection Agency (EPA) regulations demand lowering phenol content in wastewater to less than $1 \mathrm{mg} / \mathrm{L}$ [7]. There are many methods 
TABLE 1: Comparison of various CNMs adsorbents used in phenolic compounds removal.

\begin{tabular}{|c|c|c|c|c|c|}
\hline Adsorbent & Adsorbate & $T\left({ }^{\circ} \mathrm{C}\right)$ & $\mathrm{pH}$ & Model used & $\begin{array}{c}\text { Researchers and } \\
\text { reference }\end{array}$ \\
\hline MWCNT & Phenol & 37 & $5-8$ & Bimodal Langmuir & Pacholczyk et al. [26] \\
\hline $\begin{array}{l}\text { MWCNT } \\
\text { MWCNT- } \mathrm{HNO}_{3}\end{array}$ & $\begin{array}{c}\text { 2,4,6- } \\
\text { Trichlorophenol }\end{array}$ & 20 & 4 & Langmuir & Chen et al. [27] \\
\hline $\begin{array}{l}\text { MWCNT } \\
\text { MWCNT-COOH }\end{array}$ & 2-Nitrophenol & 25 & $4-11$ & Langmuir & Arasteh et al. [25] \\
\hline MWCNT- $\mathrm{H}_{2} \mathrm{O}_{2}$ & Phenol & 37 & - & Langmuir & Wiśniewski et al. [28] \\
\hline $\begin{array}{l}\text { MWCNT } \\
\text { MWCNT-COOH }\end{array}$ & $\begin{array}{c}\text { Phenol } \\
\text { 3-Chlorophenol }\end{array}$ & 20 & $5.8-6.4$ & $\begin{array}{c}\text { Competitive } \\
\text { Langmuir }\end{array}$ & Tóth et al. [29] \\
\hline $\begin{array}{l}\text { MWCNT } \\
\text { MWCNTx }\end{array}$ & $\begin{array}{c}\text { Phenol } \\
\text { Cadmium }\end{array}$ & 25 & 7 & Freundlich & Diaz-Flores et al. [17] \\
\hline $\begin{array}{l}\text { MWCNT } \\
\text { MWCNT-HNO }\end{array}$ & Chlorophenols & 25 & - & Langmuir & Liao et al. [30] \\
\hline $\begin{array}{l}\text { MWCNT } \\
\text { Modified MWCNT }\end{array}$ & Bisphenol A & $\begin{array}{c}7 \\
27 \\
47\end{array}$ & $3-9$ & $\begin{array}{c}\text { Freundlich } \\
\text { Langmuir } \\
\text { Dubinin } \\
\text { Temkin }\end{array}$ & Kuo $[31]$ \\
\hline $\mathrm{RGO}$ & Phenol & $\begin{array}{l}12 \\
40 \\
60 \\
\end{array}$ & 6.3 & $\begin{array}{l}\text { Langmuir } \\
\text { Freundlich }\end{array}$ & Li et al. [32] \\
\hline RGO & Bisphenol A & $\begin{array}{l}29 \\
49 \\
69 \\
\end{array}$ & 6 & Langmuir & Xu et al. [33] \\
\hline RGO-MNPs & Bisphenol A & $25-55$ & $3-10$ & Langmuir & Zhang et al. [34] \\
\hline $\begin{array}{l}\text { RGO } \\
\text { GEO }\end{array}$ & Phenol & 25 & $6-7$ & Freundlich & Wang et al. [35] \\
\hline GEO & Bisphenol A & 25 & 7 & Langmuir & $\mathrm{Xu}$ and $\mathrm{Zhu}[36]$ \\
\hline
\end{tabular}

available for the treatment of phenol and its derivatives, but adsorption process is the most widely used due to its relatively simple implementation and low operation cost. Researches have been carried out in order to find effective adsorbents for the treatment of phenolic waste. Therefore, there is a necessity to develop new adsorbents for removing phenol from wastewater [4]. Some reports have shown that activated carbon is considered as one of the most effective adsorbents [8]. Carbon-based nanomaterials also have novel properties that make them potentially useful in a variety of applications such as drug delivery [9, 10], lithium ion batteries [11], electrochemical and chemical sensors [12, 13], fuel cells [14], electronic devices [15], and hydrogen storage [16] and in other fields of science. The main advantages of carbon as adsorbent over other processes are the removal of both organic and inorganic compounds either by batch or column methods and the fact that it can be regenerated after repeated use. On the other hand, recent researches have demonstrated that nanomaterials exhibit high specific surface areas. This kind of materials also represents a new type of adsorbent offering an attractive option to remove organic and inorganic pollutants from water $[17,18]$. For instance, even if activated carbon fibers (ACFs) were developed as the second generation of carbonaceous adsorbents, carbon nanotubes (CNTs), with one-dimension (1D) structure, like miniaturized ACFs, may be a promising third generation of carbonaceous adsorbents [1]. In addition, thin graphene oxide (GEO) sheets have recently emerged as a new carbonbased nanoscale material and also represent an alternative in this field [19]. GEO structure is assumed to be a sheet of graphene (GE) bonded to oxygenated functional groups such as carboxyl, hydroxyl, or epoxy groups. GE is a flat single atomic layer of $\mathrm{sp}^{2}$ hybridized carbon atoms [20, 21], packed into two-dimensional (2D) honeycomb network of carbon [22, 23]. This material has attracted enormous interest due to its unique electrical and thermal conductivity, mechanical strength, optical properties, large specific surface area $\left(2630 \mathrm{~m}^{2} / \mathrm{g}\right)$, and chemical properties [24]. Thus, due to the different forms of carbon in nanometric scale, carbon nanomaterials (CNMs) have been used as adsorbents with highly promising results. Arasteh et al. have investigated the adsorption of phenolic compounds by carbon nanotubes; in addition, there are other lines of evidence that CNTs are promising adsorbents for organic pollutants [25]. In spite of the importance of these lines of evidence, only a limited number of papers have been reported on phenol adsorption by using multiwalled carbon nanotubes (MWCNT), GEO, and reduced graphene oxide (RGO). Table 1 shows a brief summary of several studies of phenolic adsorption removal using CNMs; as it can be observed, it is very difficult to compare adsorption performance of various adsorbents due to lack of similarity in the literature results. Phenol adsorption processes have been evaluated at different conditions, such as adsorbent type, phenolic compounds concentration ranges, 
temperatures, $\mathrm{pH}$, and isotherm models. These cannot be readily compared with each other.

According to Table 1, the use of CNMs as adsorbents has been studied to remove diverse phenolic pollutants; however, additional studies are needed to observe the effect of different conditions over the performance of CNMs at their different dimensions, since this allows reaching a deeper understanding of their adsorption mechanism. Besides, it is known that chemical modification produces activated carbon forms of these nanomaterials, and their adsorption performance can change depending on their surface properties. Thus, this research is focused on the performance evaluation of 1dimension (SWNTs and MWNTs) and 2-dimension (GEO and RGO) CNMs as adsorbents of phenol. CNTs were evaluated as received and after oxidation and graphene materials, GEO and RGO, were distinguished also by their attached oxygenated groups, this latter with the aim of evaluating the activated and nonactivated carbon forms as adsorbents of phenol. In this research, CNMs oxidized forms were produced by environmentally friendly methods, for instance, microwave (MW) assisted modification of CNTs, since MW irradiation has acquired a great deal of attention in domestic, industrial, and medical applications and furthermore it has been used in various environmental applications [37]. Thus, microwave (MW) assisted modification of CNTs was employed as a noninvasive, clean, and simple method, with less reaction time than conventional methods reported for the same purpose. On the other hand, chemical reduction of GEO was carried out using L-ascorbic acid (L-AA). Recently, several "green" agents, such as vitamin C (L-AA), ethylene glycol, aluminum powder, and hydrohalic acid and alkali, have been developed as the reductant reactive in the synthesis of reduced graphene oxide [38]. L-AA is naturally employed as a reductant in living things and has also been used to synthesize nanomaterials [39].

Thus, this study compares for the first time the performances of 1- and 2-dimension nanomaterials at the same conditions in the adsorption of phenol and identifies the role of different parameters such as dimension and chemical groups in the surface of carbon forms, taking into account kinetic modeling and adsorption equilibrium.

\section{Materials and Methods}

2.1. Materials. The raw SWNTs used in this study were purchased from Sigma-Aldrich (purity 40\%) with an average diameter of $0.9-1.2 \mathrm{~nm}$ and $10-30 \mu \mathrm{m}$ length and synthesized by arc discharge. MWNTs were purchased from Sun Nano Company (purity $>80 \%$,) with outer diameter of $10-30 \mathrm{~nm}$ and 1-10 $\mu \mathrm{m}$ length and produced by chemical vapor deposition (CVD). All solutions were prepared using distilled water and reagent-grade chemicals.

2.2. Oxidation of CNTs. $100 \mathrm{mg}$ of as-received CNTs was mixed with $10 \mathrm{~mL}$ of hydrogen peroxide $\left(\mathrm{H}_{2} \mathrm{O}_{2}, 30 \%\right.$, J.T.Baker); this solution was sonicated for 5 minutes until the mixture was visually homogeneous, and the mixture was introduced into a Teflon vessel and then heated in a microwave oven (Panasonic, Model NN-ST7785). The microwave power was $1200 \mathrm{~W}$ and the irradiation time was $4 \mathrm{~min}$. Previous experiments in this work showed that $1200 \mathrm{~W}$ was the most effective microwave power for this purpose. The MW irradiation was intermittent by 4 periods of 1 minute, this latter in order to avoid not only damage on the CNTs morphology or structure, but also excessive heat. These oxidized CNTs were filtered through 4-5.5 $\mu \mathrm{m}$ Millipore membrane and washed with distilled water until neutral $\mathrm{pH}$. Finally, the obtained CNTs were dried at $60^{\circ} \mathrm{C}$ for 24 hours. The obtained CNTs were designated as SWNTO and MWNTO.

2.3. Synthesis of OGE and RGO. The GEO was synthesized by oxidation of graphite powder (number 70230, Electron Microscopy Science/\#1686-BA/LOT \#1130929) using the modified Hummers method [40]. $2.0 \mathrm{~g}$ of graphite was mixed with $46 \mathrm{~mL}$ of sulphuric acid $\left(\mathrm{H}_{2} \mathrm{SO}_{4}, 98 \%\right.$, J.T.Baker $)$ in ice bath. Subsequently, $6 \mathrm{~g}$ of potassium permanganate $\left(\mathrm{KMnO}_{4}\right.$, Merck) was added slowly, and the mixture was stirred and heated for 2 hours at a constant temperature of $35^{\circ} \mathrm{C}$. Then, $92 \mathrm{~mL}$ of distilled water was added carefully to the reaction mixture and stirred for another 15 minutes. The reaction temperature was rapidly increased to $95^{\circ} \mathrm{C}$. Then, a solution of $10 \mathrm{~mL}$ of hydrogen peroxide $\left(\mathrm{H}_{2} \mathrm{O}_{2}, 30 \%\right.$, J.T.Baker $)$ in $270 \mathrm{~mL}$ of distilled water was added slowly. Finally, another solution of $10 \mathrm{~mL}$ of hydrochloric acid $(\mathrm{HCl}, 37 \%$, SigmaAldrich) in $270 \mathrm{~mL}$ of distilled water was added in order to remove the manganese salt excess. The graphite oxide (GO) was washed with distilled water to remove residual salts and acids until neutral $\mathrm{pH}$. The obtained $\mathrm{GO}$ was dried at $60^{\circ} \mathrm{C}$ for 24 hours. Then, GO was dispersed in water $(10 \mathrm{mg} / \mathrm{mL})$ and exfoliated by ultrasonication using an ultrasonic cleaner bath (Autoscience $10200 \mathrm{~B}, 40 \mathrm{KHz}$ ) for three hours, in order to obtain GEO. The GEO was dried overnight at $60^{\circ} \mathrm{C}$ in an oven.

$100 \mathrm{mg}$ of GEO was reduced with $0.3522 \mathrm{~g}$ of L-AA at $95^{\circ} \mathrm{C}$ and kept under stirring for 20 minutes to remove the majority of the oxygen functionality [41]. The obtained RGO was filtered through 4-5.5 $\mu \mathrm{m}$ Millipore membrane and washed with distilled water until neutral $\mathrm{pH}$. The obtained $\mathrm{RGO}$ were dried at $60^{\circ} \mathrm{C}$ for 24 hours in an oven.

2.4. Determination of Point of Zero Charge (PZC). The surface charge on the CNMs was determined from fast titration method using the following equation:

$$
\sigma_{o}=\frac{F\left(C_{a}-C_{b}\right)+\left[\mathrm{OH}^{-}\right]-\left[\mathrm{H}^{+}\right]}{m S},
$$

where $\sigma_{o}$ is the surface charge density $\left(\mu \mathrm{C} / \mathrm{cm}^{2}\right) ; F$ is the Faraday constant $(\mathrm{C} / \mathrm{mol}) ; C_{a}$ and $C_{b}$ are the concentrations $(\mathrm{mol} / \mathrm{L})$ of acid and base after addition to the CNMs solution; $\left[\mathrm{OH}^{-}\right]$and $\left[\mathrm{H}^{+}\right]$represent the adsorption densities of $\mathrm{OH}^{-}$ and $\mathrm{H}^{+}$as measured from the $\mathrm{pH}$ of the solution; and $m$ and $S$ refer to the mass $(\mathrm{g})$ and surface area $\left(\mathrm{m}^{2} / \mathrm{g}\right)$ of CNMs, respectively. The surface charge densities $\left(\mu \mathrm{C} / \mathrm{cm}^{2}\right)$ are plotted versus the $\mathrm{pH}$ of the suspension [42]. Potentiometric titrations of CNMs were conducted as follows: $40 \mathrm{~mL}$ of background electrolyte solution of $0.01 \mathrm{M} \mathrm{NaNO}_{3}$ containing 
$0.025 \mathrm{~g}$ of CNMs was equilibrated with continuous magnetic stirring for $60 \mathrm{~min}$. The $\mathrm{pH}$ of the system was adjusted using $0.01 \mathrm{M}$ nitric acid $\left(\mathrm{HNO}_{3}, 70 \%\right.$, Sigma-Aldrich). After $60 \mathrm{~min}$, the solution was titrated by addition of $0.2 \mathrm{~mL}$ of $0.01 \mathrm{M}$ sodium hydroxide $(\mathrm{NaOH}$, Sigma-Aldrich) using a microburet. The suspension was equilibrated for $2 \mathrm{~min}$ with constant stirring after each addition of base, and then the $\mathrm{pH}$ was recorded. At the end of the equilibration period, the change in $\mathrm{pH}$ was less than $0.01 \mathrm{pH}$ units per minute. The electrode was standardized with $\mathrm{pH} 4.0,7.0$, and 10.0 buffer solutions.

2.5. Characterization of the Carbon Nanomaterials. The morphologies of the CNMs were observed with a transmission electron microscope (JEOL JEM-1010) operating at $80 \mathrm{kV}$. The CNMs were prepared by ultrasonic dispersion in acetone. Then, drops of the suspension were put on a carbon supported TEM grid. Raman and Fourier transform infrared (FTIR) spectroscopies were analyzed in order to investigate the presence of oxygenated functional groups on the surface of CNMs. Raman spectra were obtained using Dylor LabRam II equipment (resolution $1 \mathrm{~cm}^{-1}$ ) with an excitation line of $\mathrm{He}-\mathrm{Ne}(632.8 \mathrm{~nm})$ and FTIR spectra were obtained in a spectrometer (Tensor 37, Bruker, resolution $1 \mathrm{~cm}^{-1}$ ) within the range of $4000-400 \mathrm{~cm}^{-1}$. The surface area was determined by $\mathrm{N}_{2}$ adsorption-desorption isotherms in BELSORP-mini II, BEL Japan, and using the BET equation.

2.6. Batch Kinetic and Equilibrium Studies. A stock solution of $1000 \mathrm{mg} / \mathrm{L}$ was prepared by dissolving $1.0 \mathrm{~g}$ of phenol (Sigma-Aldrich, 99\%, analytical reagent grade) in $1000 \mathrm{~mL}$ of distilled water. This stock solution was diluted to the desired initial concentrations ranging from 100 to $50 \mathrm{mg} / \mathrm{L}$. In order to select the optimum $\mathrm{pH}$ for adsorption experiments, a series of batch experiments were conducted at different $\mathrm{pH}$ range. The $\mathrm{pH}$ of the adsorbate solutions was adjusted to $5.0 \pm 0.5$ by adding few drops of $1 \mathrm{M}$ hydrochloric acid $(\mathrm{HCl}$, Sigma-Aldrich, 37\%), before mixing with the adsorbents; at this $\mathrm{pH}$ dissolved phenol is predominantly neutral. As negligible changes in the final equilibrium $\mathrm{pH}$ were observed, the uptake $\mathrm{pH}$ was assumed to be constant during the experiments. Phenol concentration was measured using UVVis spectrophotometer (DR5000, Hach) at $510 \mathrm{~nm}$ by using 4-aminoantipyrine spectrophotometric method (ASTM D 1783-01). Prior to analysis, linear calibration curves were obtained.

The kinetic experiments were performed in $100 \mathrm{~mL}$ flasks that contained $0.050 \mathrm{~g}$ of CNMs and $50 \mathrm{~mL}$ of phenol solution $(50 \mathrm{mg} / \mathrm{L})$. The mixture was ultrasonicated for $5 \mathrm{~min}$. The flasks were then covered and the solutions were kept in continuous agitation $(235 \mathrm{rpm})$ by means of a Teflon-coated stirring bar driven by a magnetic stirrer for $270 \mathrm{~min}$ at $25 \pm$ $2^{\circ} \mathrm{C}$. Samples were taken at predetermined time intervals to determine the residual concentration of the adsorbate and the equilibrium time for phenol adsorption. Before analysis, samples were centrifuged at $3500 \mathrm{rpm}$ for $10 \mathrm{~min}$, and the supernatant was filtered. All adsorption experiments were performed in triplicate under identical conditions and average values were used for further calculations.

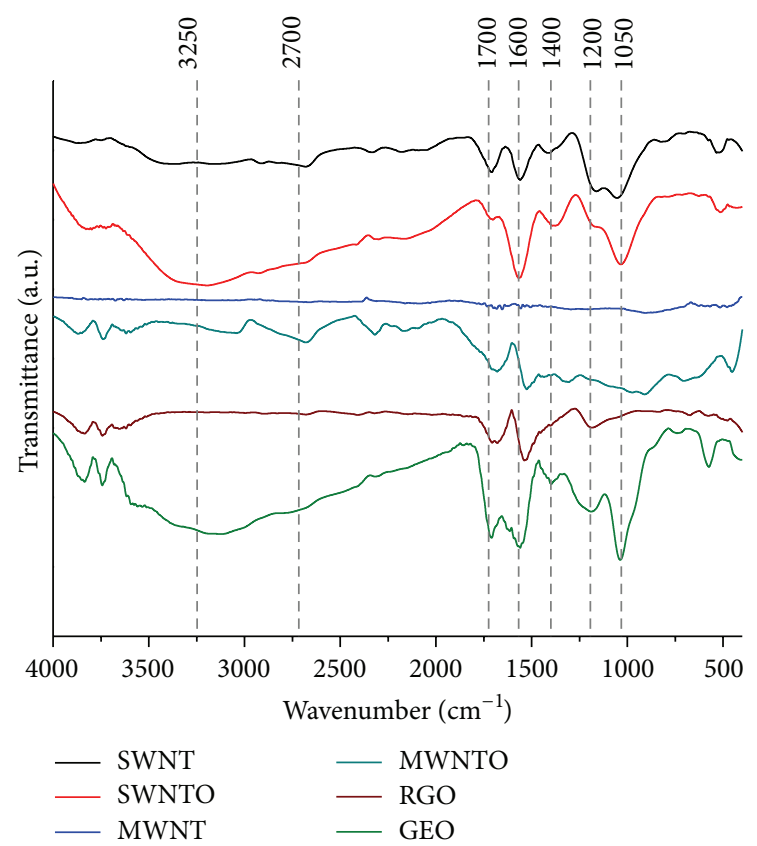

FIGURE 1: FTIR of as-received and modified CNTs, RGO, and GEO.

The uptake of the adsorbate was calculated by the following equation:

$$
q_{t}=\frac{V\left(C_{0}-C_{t}\right)}{m},
$$

where $q_{t}$ is the adsorption capacity per gram of the adsorbent at time $t, V$ is the volume of the solution $(\mathrm{L}), C_{0}$ is the initial concentration of the adsorbate $(\mathrm{mg} / \mathrm{L}), C_{t}$ is the concentration of the adsorbate $(\mathrm{mg} / \mathrm{L})$ in solution at time $t$, and $m$ is the mass of adsorbent (g) [43].

The equilibrium studies were performed using the following procedure at $25 \pm 2^{\circ} \mathrm{C}$ : parallel series of batch adsorption tests were carried out in $100 \mathrm{~mL}$ flasks; $50 \mathrm{~mL}$ of adsorbate solutions $(10,20,30,40,50$, and $60 \mathrm{mg} / \mathrm{L})$ of phenol was independently added to $0.050 \mathrm{~g}$ of CNMs. The mixture was ultrasonicated for 5 minutes and shaken. Preliminary adsorption experiments were performed to determine the equilibrium time, reached at 100 minutes.

The uptake of the adsorbate at equilibrium was calculated by the following equation:

$$
q_{e}=\frac{V\left(C_{0}-C_{e}\right)}{m},
$$

where $q_{e}$ is the equilibrium adsorption capacity per gram of adsorbent $(\mathrm{mg} / \mathrm{g}), C_{e}$ is the equilibrium concentration of adsorbate $(\mathrm{mg} / \mathrm{L})$, and $V, C_{0}$, and $m$ have the same meaning as before [8].

\section{Results and Discussion}

Figure 1 shows the FTIR spectra of as-received and modified CNTs, RGO, and GEO. It is clear that MWNTs do not display significant bands, but SWNTs show some signals that indicate 
the presence of functional groups such as $v(\mathrm{OH})$ at $3250 \mathrm{~cm}^{-1}$ related to hydroxyl groups, $v(\mathrm{C}=\mathrm{O})$ at $1700 \mathrm{~cm}^{-1}$ associated with carboxylic groups, and $v(\mathrm{C}=\mathrm{O})$ at $1400 \mathrm{~cm}^{-1}$ presented in ketone groups; the peak around $1600 \mathrm{~cm}^{-1}$ corresponds to $v(\mathrm{C}=\mathrm{C})$ of the graphitic $\mathrm{sp}^{2}$ bonds. The formation of functional groups on the SWNTO and MWNTO surface after microwave irradiation is confirmed by the FTIR. In the case of MWNTO, the peaks at $1600 \mathrm{~cm}^{-1}, 1700 \mathrm{~cm}^{-1}$, $2700 \mathrm{~cm}^{-1}$, and $3200 \mathrm{~cm}^{-1}$ appear in the spectrum. These peaks are assigned to $v(\mathrm{C}=\mathrm{O})$ related to carboxylate groups, $v(\mathrm{C}=\mathrm{O})$ from carboxylic groups, $v(\mathrm{C}=\mathrm{O})$ from aldehyde groups, and $v(\mathrm{OH})$ from hydroxyl groups, respectively. In Figure 1, SWNTO spectrum shows several peaks at $3200 \mathrm{~cm}^{-1}, 1700 \mathrm{~cm}^{-1}, 1600 \mathrm{~cm}^{-1}$, and $1400 \mathrm{~cm}^{-1}$ similar to MWNTO spectrum. Evidently, various functional groups were generated on the surface of modified CNTs, providing various adsorption sites.

The oxidative treatment not only produces damage in the carbon defect sites but also creates additional defects that also can be oxidized [44]; the FTIR spectra indicate that hydrogen peroxide treatment introduced more oxygencontaining functional groups on the outermost surface and defect sites that increase the hydrophilicity of CNTs. Similarly, the surface modification improves the dispersion of CNMs in solution, which could increase the removal capacity of pollutants.

Similarly, the spectrum of GEO shows a broad absorption band at $3200 \mathrm{~cm}^{-1}$ indicating the presence of $v(\mathrm{OH})$, which is related to the hydroxyl groups. The other oxygenated functional groups of GEO are displayed by the bands around $1050 \mathrm{~cm}^{-1}, 1200 \mathrm{~cm}^{-1}, 1400 \mathrm{~cm}^{-1}$, and $1700 \mathrm{~cm}^{-1}$; these bands correspond to $v(\mathrm{C}-\mathrm{O})$ from epoxy groups, $v(\mathrm{C}-\mathrm{O})$ associated with phenol groups, $v(\mathrm{C}=\mathrm{O})$ related to carboxylate groups, and $v(\mathrm{C}=\mathrm{O})$ from carboxylic groups, respectively. The peak at $1630 \mathrm{~cm}^{-1}$ can be assigned to the contributions from the skeletal vibrations of unoxidized graphitic domains [38]. In contrast, after the reduction of GEO with L-AA (RGO spectrum), the absorption band of $v(\mathrm{OH})$ at $3200 \mathrm{~cm}^{-1}$ disappears completely. Moreover, there is a decrease in the intensities of the peaks corresponding to the oxygenated groups, such as $v(\mathrm{C}=\mathrm{O})$ at $1700 \mathrm{~cm}^{-1}, v(\mathrm{C}=\mathrm{O})$ at $1400 \mathrm{~cm}^{-1}$, and $v(\mathrm{C}-\mathrm{O})$ at $1200 \mathrm{~cm}^{-1}$ previously mentioned; this demonstrates that most of the functional groups are removed.

Raman spectroscopy is a powerful nondestructive technique widely used to distinguish ordered and disordered crystal structures of carbon. The CNTs samples have similar Raman scattering patterns. Raman spectra of CNTs and CNTOs (Figures 2(a)-2(b)) show two characteristic peaks around $1585 \mathrm{~cm}^{-1}$ (G band) and $1340 \mathrm{~cm}^{-1}$ (D band). The D band is due to defect sites in the hexagonal framework of walls of CNTs [27], and the G band reflects the structural intensity of the $\mathrm{sp}^{2}$ hybridized carbon atoms. The intensity ratio $\left(I_{\mathrm{D}} / I_{\mathrm{G}}\right)$ can be used as an indicator for the structural intensity of the $\mathrm{sp}^{2}$ hybridized carbon atoms [45]. $I_{\mathrm{D}} / I_{\mathrm{G}}$ ratio normally increases with covalent functionalization, since the creation of covalent bonds between carbon on the nanotube surface and functional groups modifies the hybridization of carbon towards greater $\mathrm{sp}^{3}$ character [46]. Oxidative treatment with hydrogen peroxide increases $I_{\mathrm{D}} / I_{\mathrm{G}}$ ratio from 0.46 for SWNT to 0.50 for SWNTO by eliminating amorphous carbon and modifying chemically the surface of SWNT. The intensity ratio is 1.17 and 1.26 for MWNT and MWNTO, respectively, similar to SWNT; thus, the removal of amorphous carbon and metals adds purity to the nanomaterial. $I_{\mathrm{D}} / I_{\mathrm{G}}$ ratio is increased after the functionalization reaction. This observation confirms the covalent functionalization of CNTs using microwave irradiation.

Raman spectra of GEO and RGO are also shown in Figure 2(c). Raman spectroscopy of graphene is generally characterized by the two bands mentioned before in carbon nanotubes; the $\mathrm{G}$ band is related to $\mathrm{sp}^{2}$ carbon atoms (generally observed at $1575 \mathrm{~cm}^{-1}$ ); and the $\mathrm{D}$ band at $1350 \mathrm{~cm}^{-1}$ corresponds to defects in the curved graphene sheet [23].

The $\mathrm{G}$ band in GEO spectrum appears at $1596 \mathrm{~cm}^{-1}$ and the $\mathrm{D}$ band at $1328 \mathrm{~cm}^{-1}$. After reduction (RGO spectrum), the $\mathrm{G}$ band appears at $1588 \mathrm{~cm}^{-1}$ and the $\mathrm{D}$ band at $1320 \mathrm{~cm}^{-1}$. In addition, both bands are broader in GEO than in RGO. The presence of $\mathrm{D}$ and $\mathrm{G}$ bands at higher frequencies and the broadening are general observations of disorder [47]. Thus, the red-shifted and narrower peaks in RGO spectrum are clear signals of graphitic order recovery. On the other hand, the intensity ratio for GEO is 1.487 . In comparison, $I_{\mathrm{D}} / I_{\mathrm{G}}$ ratio of the RGO has been increased to $1.724 ; I_{\mathrm{D}} / I_{\mathrm{G}}$ increment is explained by the presence of small crystallites or graphitic domains, where borders act as defects [48].

Figure 3 exhibits a comparison of the TEM images of asreceived CNTs (Figure 3(a)) and CNTOs (Figures 3(b)-3(d)); some changes in amorphous carbon contained on CNTs are observed in the images after modification (Figures 3(b) and $3(d))$. It is possible to observe in these CNTOs images that the functionalization produces opening up of the tube ends (Figure 3(b)), generates defects on the sidewalls of nanotubes, and shortens long tubes (Figure 3(d)). However, the nanotube diameter does not present changes after oxidation by microwave irradiation. TEM micrographs of GEO and RGO are shown in Figures 3(e) and 3(f), respectively. Both GEO and RGO exhibit a typically wrinkled, sheet-like structure. The morphological structure of the RGO shows no difference from the GEO.

Previous works have shown that microwaves have no direct effect on the morphology or structure of CNTs [46, 49]. The main advantage of combining MW with chemical oxidants is the stimulation of free radical generation. High reaction temperature could be reached within a short time frame when MW and oxidants are combined; this is observed when comparing MW process to the traditional thermal or catalytic oxidation methods [37]. Rate improvements may be achieved under microwave heating due to mixing effects; this is explained taking into account the fact that the rapid molecular rotation of the solvent/solute boundary layer induced by the electric field provides efficient localised mixing at molecular level. Microwave irradiation may cause heating by two main factors: (1) dipolar polarization and (2) conduction (joule heating). Different authors reached a consensus about reagent-free MW based method for purification 


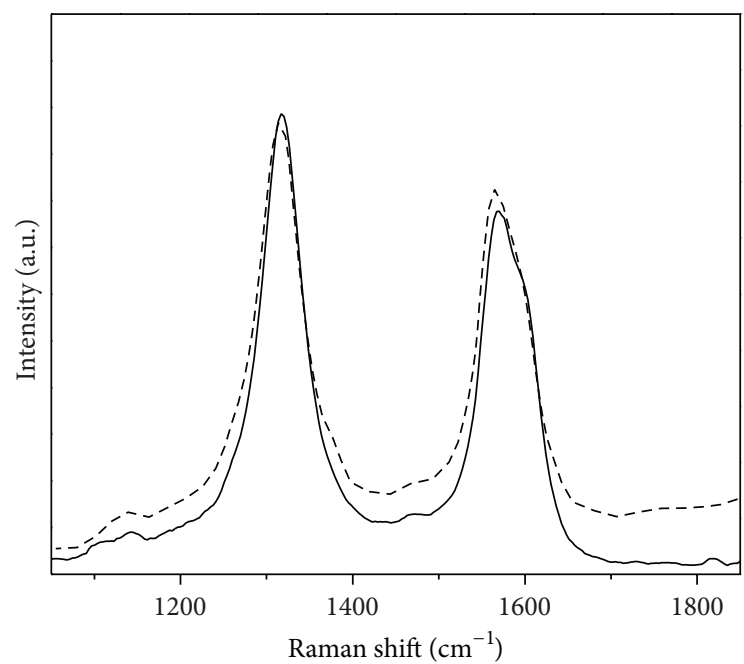

MWNT MWNTO

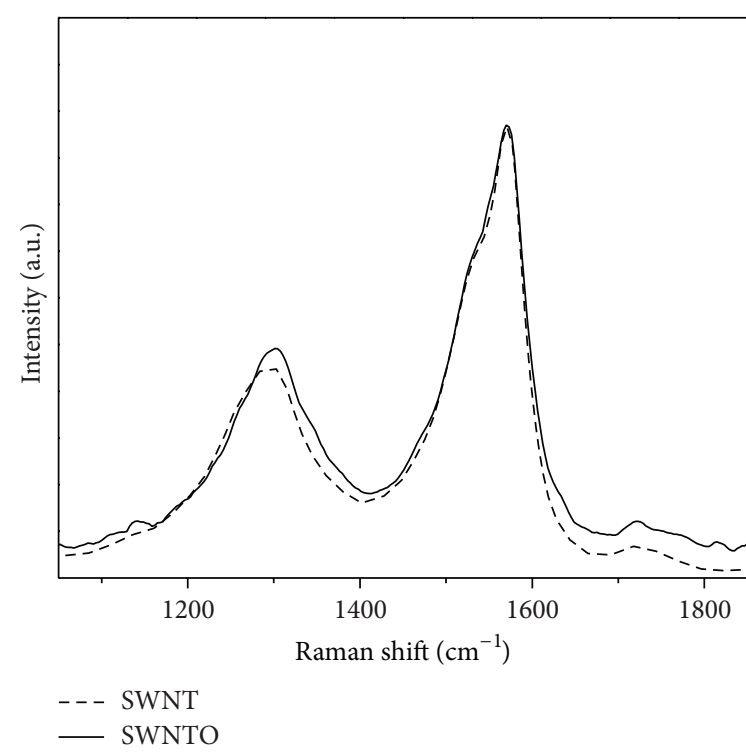

(b)

(a)

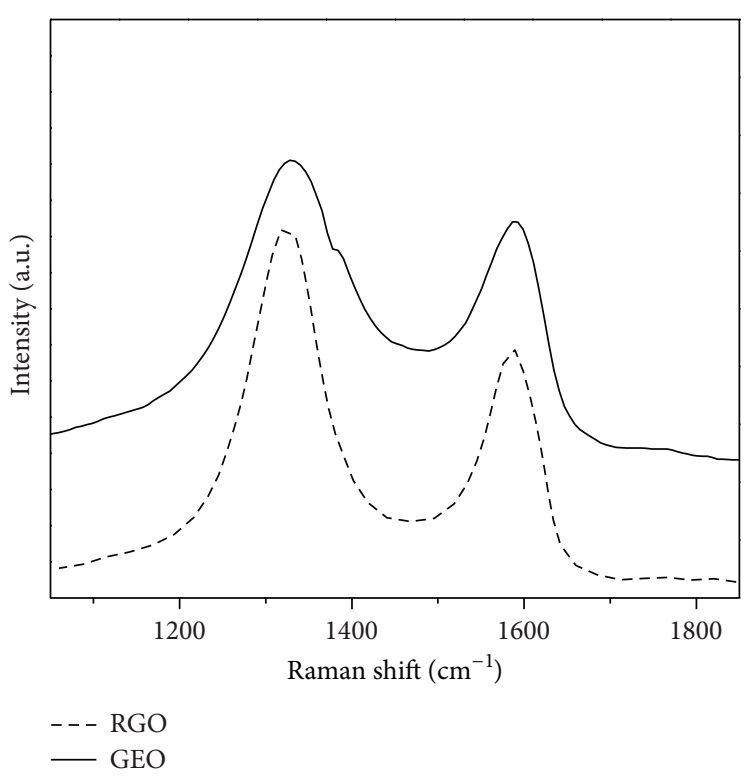

(c)

FIgURE 2: Raman spectra for (a) MWNTs and (b) SWNTs before and after microwave treatment and (c) RGO and GEO.

of MWNTs as a promising process with advantages such as being extremely fast, having significantly less damage to CNTs, and producing less harmful waste when compared with previously reported conventional approaches [50, 51].

The specific surface areas (SSA) were calculated using the BET method. The SSA values are 64, 204, 136, 113, 48, and $186 \mathrm{~m}^{2} / \mathrm{g}$ for SWNT, SWNTO, MWNT, MWNTO, RGO, and GEO, respectively. The SSA values play an important role in the adsorption of phenol by CNMs; this effect is discussed in the next sections after removal experiments. Functionalization modifies the physical properties of the CNTs such as SSA and pore size distribution. After oxidation, mean pore diameter increases from $8.74 \mathrm{~nm}$ for SWNT to $16.74 \mathrm{~nm}$ for SWNTO; a similar effect is observed for as-received MWNT from 30.58 to $35.33 \mathrm{~nm}$ for MWNTO, and also RGO with $18.508 \mathrm{~nm}$ is amply exceeded by GEO with $31.58 \mathrm{~nm}$. This indicates the presence of mesopores $(2-50 \mathrm{~nm})$ in all adsorbents.

The solution $\mathrm{pH}$ is a key factor that also influences the adsorption capacity of phenol on the active sites of CNMs [31]. $\mathrm{pH}$ primarily affects the ionization degree of the phenolic sorbate. The surface charge can depend on the $\mathrm{pH}$ solution and the surface characteristics of carbon [2]. In previous experiments of this work, it was observed that phenol removal decreases with an increase in the solution $\mathrm{pH}$ (not shown here); this is due to phenol charge changes with $\mathrm{pH}$ value. It is known that $\mathrm{p} K_{\mathrm{a}}$ value of phenol is 9.99; hence, phenol is considered as a neutral molecule below 


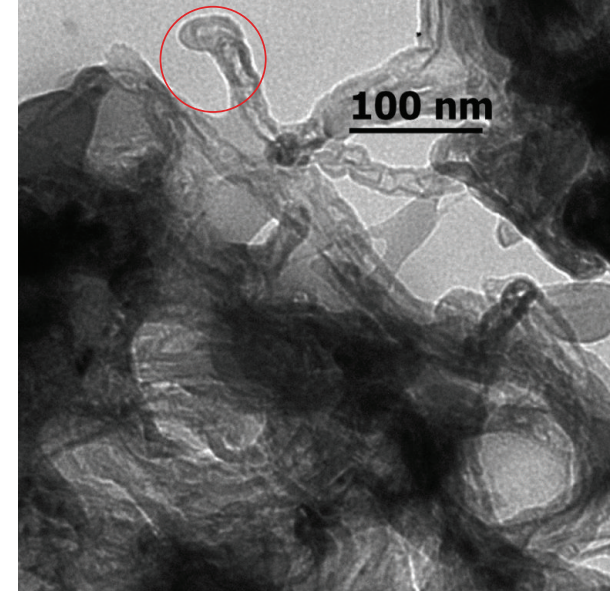

(a)

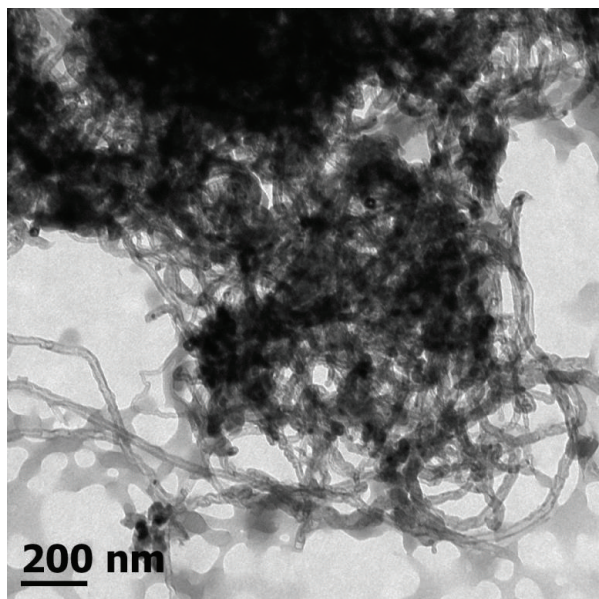

(c)

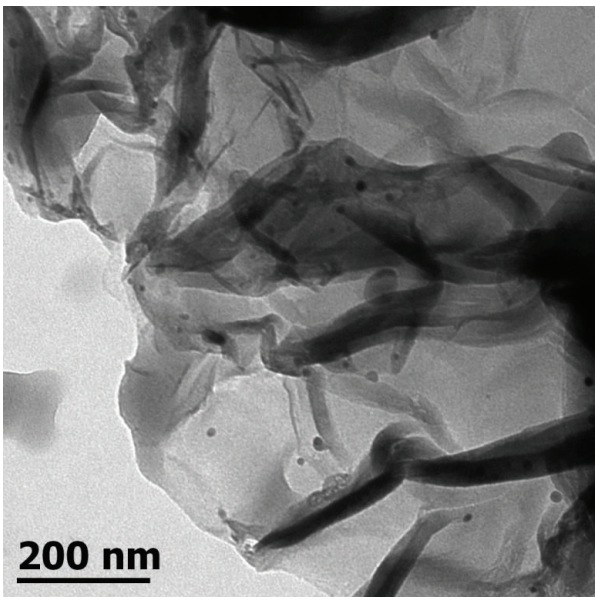

(e)

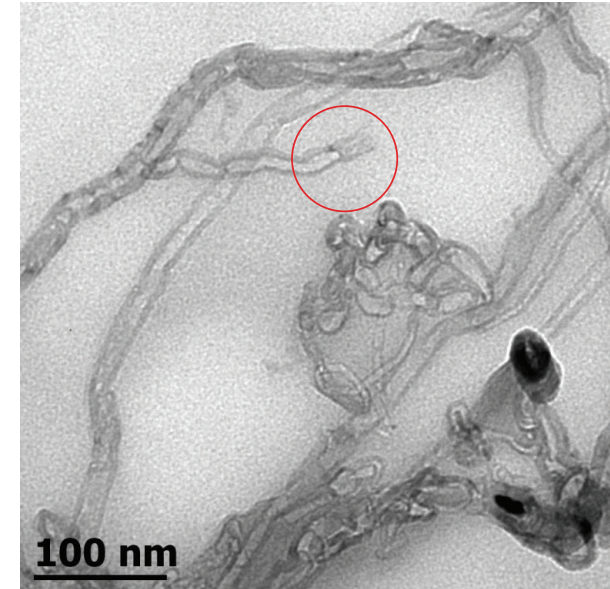

(b)

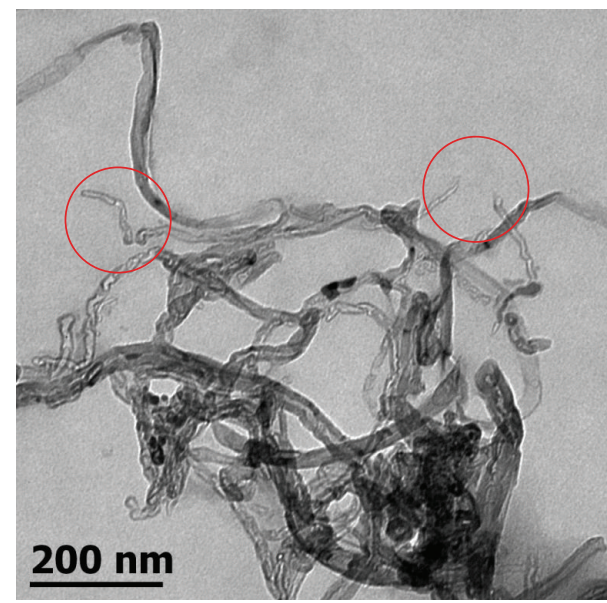

(d)

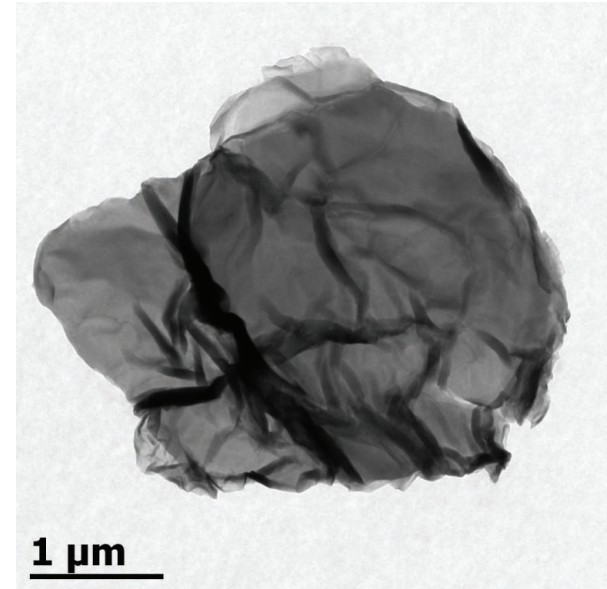

(f)

Figure 3: TEM micrographs of (a) MWCNT, (b) MWNTO, (c) SWNT, (d) SWNTO, (e) RGO, and (f) GEO.

this $\mathrm{pH}$ and above this value is found as anionic species (phenolate) [17]. The phenolate anions are more soluble in aqueous solution, and consequently stronger adsorbatewater bonds must be broken before adsorption can take place [25]. Thereby, the phenol solution $\mathrm{pH}$ is adjusted at $5.0 \pm 0.5$ in order to achieve the appropriate condition for adsorption. Thus, the phenol molecules adsorbed onto CNMs are neutral and not phenolate anions. The potentiometric (acid/base) titration technique was employed to determine the PZC of CNMs. The PZC values are 6.11, 7.01, 4.63, 6.59, 3.17, and 5.24 

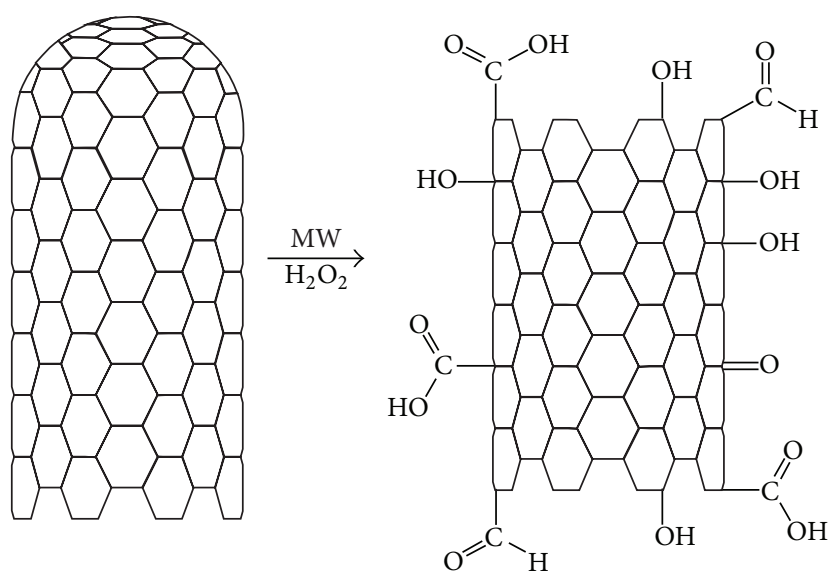

FIGURE 4: Schematic representation of CNT before and after MW treatment.

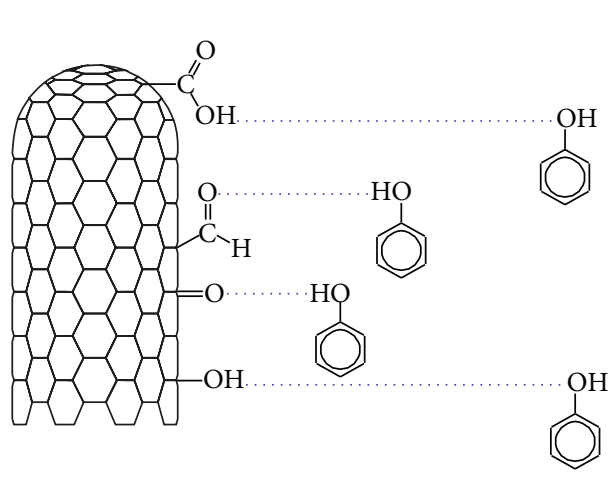

Hydrogen bonding

(a)

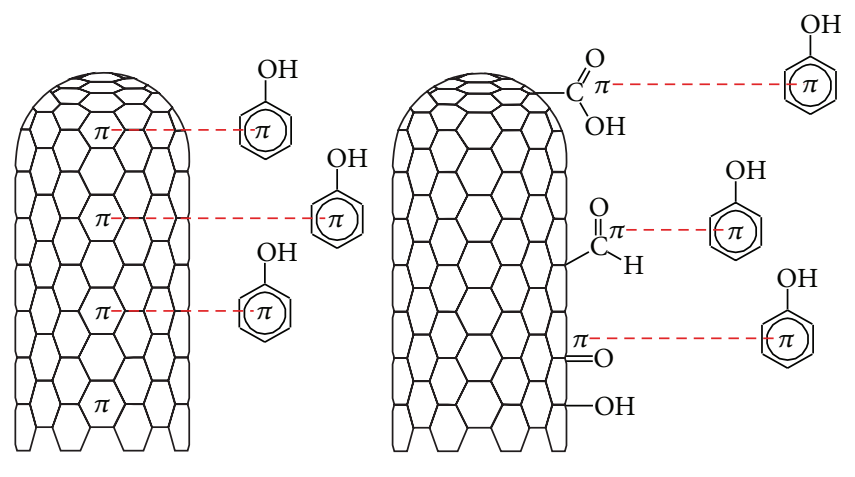

$---\pi-\pi$ interaction

(b)

FIgURE 5: Mechanism of interaction between CNT and CNTO with phenol.

for MWNTO, MWNT, SWNTO, SWNT, GEO, and RGO, respectively. The $\mathrm{PZC}$ represents the $\mathrm{pH}$ at which the charge of the solid is zero, that is, the $\mathrm{pH}$ at which the charge of the positive sites equals that of the negative ones. At $\mathrm{pH}<$ PZC, the surface charge of the material is positive and at $\mathrm{pH}>\mathrm{PZC}$, the surface charge of the material is negative [4]. Numerous investigations have demonstrated that the PZC values for oxidant-modified CNTs are more negative than those of as-grown CNTs [31]. According to the results obtained in this research for PZC, it is possible to assume that the surface of modified CNTs is more negatively charged mainly due to the presence of more carboxylic, hydroxyl, and small quantity of aldehyde and ketone groups produced by hydrogen peroxide (Figure 4), which promote the adsorption of phenol by modified CNTs, through hydrogen bonding as illustrated in Figure 5(a). The mechanism of interaction between RGO and GEO with phenol is similar to CNT and CNTO.

On the other hand, phenol is an organic compound that contains an aromatic ring in its structure, and this can be retained by CNMs due to weak interactions between delocalized electrons, as in the case of unmodified carbon nanotubes. In addition, modified carbon nanotubes also can adsorb phenol molecules by $\pi-\pi$ interactions between carbonyl groups and aromatic rings (Figure 5(b)).

In order to understand clearly the phenomena involved in phenol adsorption on CNMs, the rate of the adsorption process and the rate-controlling step are studied using kinetic models. In addition, it is necessary to take into account the fact that the mechanism of adsorption depends on the physical and/or chemical characteristics of the adsorbent as well as on the mass transport process.

3.1. Kinetic Modeling. Experimental data must be analyzed considering the correct identification of the ratedetermining step that controlled the adsorption process. There are three consecutive steps involved in the adsorption of organic/inorganic species by a porous adsorbent: (1) transport of the adsorbate to the external surface of the adsorbent; (2) transport of the adsorbate within the pores of the adsorbent except for a small amount of adsorption that occurs on the external surface; (3) adsorption of the adsorbate on the external surface of the adsorbent. It is generally accepted that step (3) is very fast and does not represent the rate-determining step in the uptake of organic species [2]. In order to investigate the mechanism of phenol 
adsorption onto CNMs, pseudo-first-order, pseudo-secondorder, Elovich, and intraparticle diffusion models are considered to fit the experimental data obtained from batch studies and the correlation coefficient $\left(R^{2}\right)$ is considered as a measurement of the relationship between the experimental data and these proposed models.

3.2. Pseudo-First-Order Model or Lagergren's Equation. The pseudo-first-order rate expression is based on the adsorption capacity of adsorbent and may be written as

$$
\frac{d q}{d t}=k_{1}\left(q_{e q}-q\right)
$$

The integrated form of the differential equation becomes

$$
\log \left(q_{e}-q_{t}\right)=\log q_{e}-\frac{k_{1}}{2.303} t
$$

where $q_{e}$ and $q_{t}(\mathrm{mg} / \mathrm{g})$ are the amounts of phenol adsorbed at equilibrium and at time $t$, respectively, and $k_{1}\left(\mathrm{~min}^{-1}\right)$ is pseudo-first-order rate constant. The adsorption rate parameter $k_{1}$ can be calculated by plotting $\log \left(q_{e}-q_{t}\right)$ versus $t$ $[25,52]$.

3.3. Pseudo-Second-Order Model. The adsorption kinetic may also be described by pseudo-second-order equation, which is based on the adsorption capacity of solid phase. The equation is expressed as follows:

$$
\frac{d q}{d t}=k_{2}\left(q_{e}-q\right)^{2}
$$

The integrated form of the differential equation becomes

$$
\frac{t}{q}=\frac{1}{k_{2} q_{e}^{2}}+\frac{1}{q_{e}} t
$$

where $q_{e}$ and $q_{t}$ have the same meaning as before and $k_{2}$ is the pseudo-second-order rate constant ( $\mathrm{g} /(\mathrm{mg} \mathrm{min}))$.

If pseudo-second-order kinetic equation is applicable, the plot of $t / q$ versus $t$ should give a linear behavior. $q_{e}$ can be calculated from the slope of this graphic and $k_{2}$ is deduced from the intercept of theline [52].

3.4. Elovich Model. Elovich model is another widely used model to describe the adsorption process, which supposes that the adsorbate is adsorbed on the solid surface without desorption, and the adsorption rate decreases with increasing contact time due to increased surface coverage. The equation can be expressed as

$$
\frac{d q_{t}}{d t}=\alpha \exp \left(-\beta q_{t}\right)
$$

Integration of the Elovich equation with boundary conditions, $q_{t}=q_{t}$ at $t=t$ and $q_{t}=0$ at $t=0$, is represented by

$$
q_{t}=\frac{1}{\beta} \ln (\alpha \beta)+\frac{1}{\beta} \ln \left(t+t_{o}\right),
$$

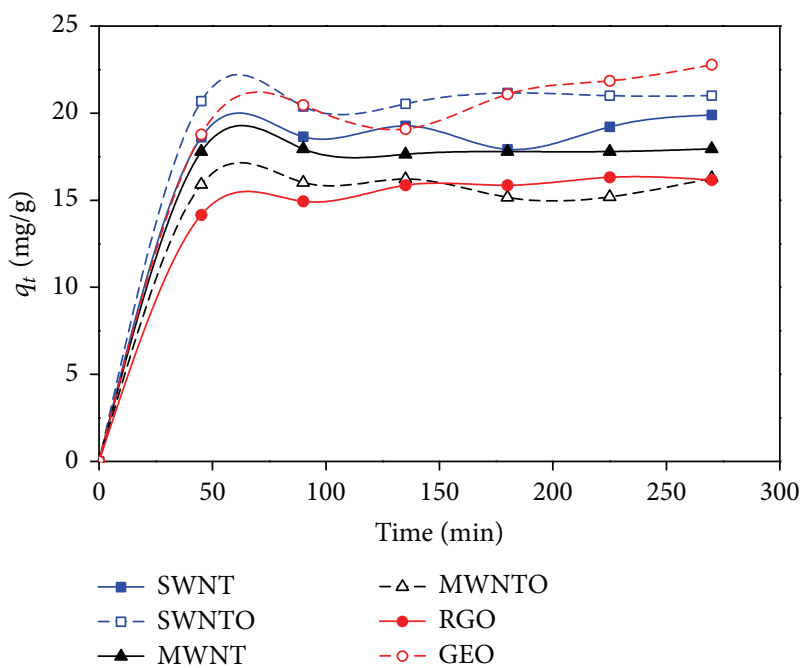

FIGURE 6: Adsorption kinetics of phenol on carbon nanomaterials $\left(C_{0}=50 \mathrm{mg} / \mathrm{L}, T=25 \pm 2^{\circ} \mathrm{C}, \mathrm{pH}=5.0 \pm 0.5\right)$.

where $q_{t}$ is the adsorbed phenol ( $\left.\mathrm{mg} / \mathrm{g}\right)$ at time $t$ ( $\left.\mathrm{min}\right), \alpha$ is the initial adsorption rate $(\mathrm{mg} /(\mathrm{g} \min ))$, and $\beta$ is related to the activation energy for chemisorption ( $\mathrm{g} / \mathrm{mg}$ ).

Assuming that $\alpha \beta t \gg 1$ and applying the boundary condition $q_{t}=0$ at $t=0$, it can be rewritten as

$$
q_{t}=\frac{1}{\beta} \ln (\alpha \beta)+\frac{1}{\beta} \ln t .
$$

If this equation applies, it should lead to a straight line by plotting $q_{t}$ as a function of $\ln t$ [53].

3.5. Intraparticle Diffusion Model. Since neither pseudo-firstorder nor pseudo-second-order models can identify the diffusion mechanism, the intraparticle diffusion model is used to investigate the diffusion controlled adsorption system. The intraparticle diffusion equation is expressed in the following form:

$$
q_{t}=k_{\mathrm{id}} t^{1 / 2}+\theta
$$

where $k_{\mathrm{id}}$ is the intraparticle diffusion rate constant $\left(\mathrm{mg} / \mathrm{g} \min ^{1 / 2}\right)$, which can be deduced from the slope of the linear plot of $q_{t}$ versus $t^{1 / 2}$, and the intercept of the line $\theta$ denotes the thickness value from the boundary layer $(\mathrm{mg} / \mathrm{g})$ [31].

Figure 6 shows the adsorption kinetics andthe effect of contact time on phenol adsorption on CNMs. The results indicate that most of the phenol removal takes place during the first $50 \mathrm{~min}$. The adsorption equilibrium of phenol is achieved after 100 minutes and no remarkable changes are observed for longer contact time.

It is implied that carbon nanomaterials possess very strong adsorption ability for phenol. The removal obtained is $38,42,35,32,41$, and $31 \%$ with SWNT, SWNTO, MWNT, MWNTO, GEO, and RGO, respectively, at $50 \mathrm{mg} / \mathrm{L}$ of initial concentration. The adsorption capacity is strongly induced by the number of available active sites, which initially is higher; 
TABLE 2: Adsorption parameters of the kinetic models.

\begin{tabular}{lcccccccc}
\hline & & \multicolumn{2}{c}{ Pseudo-first-order } & \multicolumn{2}{c}{ Pseudo-second-order } & \multicolumn{2}{c}{ Elovich } & \multicolumn{2}{c}{ Intraparticle diffusion } \\
& $\begin{array}{c}q_{e} \\
\text { exp. }\end{array}$ & $\begin{array}{c}q_{e} \\
\text { calc. }\end{array}$ & $R^{2}$ & $\begin{array}{c}q_{e} \\
\text { calc. }\end{array}$ & $R^{2}$ & $R^{2}$ & $\theta$ & $R^{2}$ \\
\hline SWNT & 19.898 & 5.525 & 0.467 & 19.841 & 0.993 & 0.188 & 17.823 \\
SWNTO & 21.163 & 4.222 & 0.663 & 21.231 & 1.000 & 0.394 & 20.102 & 0.232 \\
MWNT & 17.948 & 5.425 & 0.666 & 17.921 & 1.000 & 0.013 & 17.752 & 0.461 \\
MWNTO & 16.276 & 1.617 & 0.112 & 15.773 & 0.994 & 0.047 & 16.131 & 0.041 \\
RGO & 16.316 & 7.099 & 0.884 & 16.807 & 1.000 & 0.946 & 12.896 & 0.900 \\
GEO & 22.781 & 11.937 & 0.787 & 23.697 & 0.991 & 0.708 & 16.094 & 0.766 \\
\hline
\end{tabular}

therefore, the adsorbate reaches the active sites with ease; subsequently, the number of active sites decreases and the adsorbent surface becomes saturated.

The mechanism to describe phenol adsorption on CNMs as adsorbents is based on their electronic structures, which possess essentially $\mathrm{sp}^{2}$ orbitals. Thus, it is possible to postulate that the adsorption mechanism for this system involves interactions between $\pi$ electrons that are delocalized on the carbon surface structure and $\pi$ electrons of the aromatic ring.

The values of adsorption parameters derived from the application of the kinetic models are presented in Table 2. For each case, the corresponding regression coefficients, $R^{2}$, are given.

Calculated and experimental values of $q_{e}$ are given in Table 2; these results show that the correlation coefficients for the pseudo-second-order kinetic model are higher than those obtained for the pseudo-first-order, Elovich, and intraparticle diffusion models. In view of these results, it can be said that the pseudo-second-order kinetic model provides better correlation for phenol adsorption onto CNMs in contrast to the other models. The results show that $R^{2}$ values obtained with the pseudo-second-order model are higher than 0.99 .

Banat et al. [5] had reported that if intraparticle diffusion is involved in the sorption process, then a graphic of adsorbate uptake versus the square root of time would result in a linear relationship and the intraparticle diffusion would be the rate-controlling step if this line passes through the origin. The results (Table 2 ) can be represented by a linear relationship; however, the line does not pass through the origin. This indicates that intraparticle diffusion is involved in the sorption process but it is not the only rate-limiting mechanism and also other mechanisms are involved.

3.6. Modeling of the Adsorption Isotherms. In addition to the models discussed before, equilibrium studies provide information on the adsorption capacity of the adsorbent; therefore, they are also necessary to complete the understanding of these novel nanomaterials as adsorbents. An adsorption isotherm is characterized by certain constant values, which express the surface properties and the affinity of the adsorbent and can also be used to compare the adsorptive capacities of the adsorbent for different pollutants. Several mathematical models can be used to describe experimental data of adsorption isotherms. The Langmuir and Freundlich models are used to fit the adsorption isotherms and to evaluate the isotherm parameters.
3.7. Langmuir Isotherm. The Langmuir isotherm considers several assumptions: the adsorption is localized, all the active sites on the surface have similar energies, there are no interactions between adsorbed molecules, and the limiting reaction step is the surface reaction.

The Langmuir model is valid for monolayer adsorption onto a surface with a finite number of adsorption sites, which are homogeneously distributed over the adsorbent surface with no transmigration of adsorbate in the pores of the adsorbent surface.

The Langmuir model may be written as

$$
q_{e}=\frac{q_{\max } K_{L} C_{e}}{1+K_{L} C_{e}},
$$

where $q_{e}$ is the adsorption capacity of the adsorbate per unit weight of adsorbent $(\mathrm{mg} / \mathrm{g}), q_{\max }$ is the maximum adsorption capacity $(\mathrm{mg} / \mathrm{g}), K_{L}$ is the constant related to the free energy of adsorption $(\mathrm{L} / \mathrm{mg})$, and $C_{e}$ is the equilibrium concentration of the adsorbate $(\mathrm{mg} / \mathrm{L})$ [54].

The linearized form of the Langmuir model is

$$
\frac{C_{e}}{q_{e}}=\frac{1}{q_{\max } K_{L}}+\frac{1}{q_{\max }} C_{e} .
$$

A graphic of $C_{e} / q_{e}$ versus $C_{e}$ indicates a straight line of slope $1 / q_{\max }$ and intercept of $1 / q_{\max } K_{L}[32]$.

3.8. The Freundlich Model. The Freundlich model is an empirical equation that describes the equilibrium on sorption on heterogeneous surface through a multilayer adsorption mechanism [52].

The Freundlich model may be written as

$$
q_{e}=K_{F} C_{e}^{1 / n}
$$

where $q_{e}$ is the equilibrium amount of the adsorbate per unit mass of adsorbent ( $\mathrm{mg} / \mathrm{g}), C_{e}$ is the equilibrium concentration of the adsorbate $(\mathrm{mg} / \mathrm{L})$, and $K_{F}$ is a constant that indicates the adsorption capacity of the adsorbent at unit concentration $\left(\mathrm{mg} / \mathrm{g}(\mathrm{L} / \mathrm{mg})^{1 / n}\right)$, while $1 / n$ indicates the intensity of the adsorption.

The linearized form of the Freundlich model is

$$
\log q_{e}=\log K_{F}+\frac{1}{n} \log C_{e} .
$$


TABLE 3: Isotherm parameters and the correlation coefficient for the adsorption of phenol on CNMs.

\begin{tabular}{|c|c|c|c|c|c|c|c|c|}
\hline \multirow{2}{*}{ Adsorbent } & \multirow{2}{*}{$C_{0}(\mathrm{mg} / \mathrm{L})$} & \multicolumn{4}{|c|}{ Langmuir } & \multicolumn{3}{|c|}{ Freundlich } \\
\hline & & $q_{\max }(\mathrm{mg} / \mathrm{g})$ & $K_{L}(\mathrm{~L} / \mathrm{mg})$ & $R_{L}$ & $R^{2}$ & $K_{F}(\mathrm{mg} / \mathrm{g})(\mathrm{L} / \mathrm{mg})^{1 / n}$ & $1 / n$ & $R^{2}$ \\
\hline \multirow{6}{*}{ SWNT } & 10 & \multirow{6}{*}{25.126} & \multirow{6}{*}{0.201} & 0.499 & \multirow{6}{*}{0.968} & \multirow{6}{*}{7.909} & \multirow{6}{*}{0.294} & \multirow{6}{*}{0.985} \\
\hline & 20 & & & 0.249 & & & & \\
\hline & 30 & & & 0.166 & & & & \\
\hline & 40 & & & 0.125 & & & & \\
\hline & 50 & & & 0.100 & & & & \\
\hline & 60 & & & 0.083 & & & & \\
\hline \multirow{6}{*}{ SWNTO } & 10 & \multirow{6}{*}{30.864} & \multirow{6}{*}{0.120} & 0.833 & \multirow{6}{*}{0.967} & \multirow{6}{*}{6.074} & \multirow{6}{*}{0.410} & \multirow{6}{*}{0.994} \\
\hline & 20 & & & 0.417 & & & & \\
\hline & 30 & & & 0.278 & & & & \\
\hline & 40 & & & 0.208 & & & & \\
\hline & 50 & & & 0.167 & & & & \\
\hline & 60 & & & 0.139 & & & & \\
\hline \multirow{6}{*}{ MWNT } & 10 & \multirow{6}{*}{25.381} & \multirow{6}{*}{0.142} & 0.704 & \multirow{6}{*}{0.975} & \multirow{6}{*}{6.162} & \multirow{6}{*}{0.353} & \multirow{6}{*}{0.994} \\
\hline & 20 & & & 0.352 & & & & \\
\hline & 30 & & & 0.235 & & & & \\
\hline & 40 & & & 0.176 & & & & \\
\hline & 50 & & & 0.141 & & & & \\
\hline & 60 & & & 0.117 & & & & \\
\hline \multirow{6}{*}{ MWNTO } & 10 & & & 0.817 & & & & \\
\hline & 20 & & & 0.408 & & & & \\
\hline & 30 & 19.608 & 0.122 & 0.272 & 0.985 & 4.777 & 0.337 & 0.998 \\
\hline & 40 & & & 0.204 & & & & \\
\hline & 50 & & & 0.163 & & & & \\
\hline & 60 & & & 0.136 & & & & \\
\hline & 10 & & & 0.980 & & & & \\
\hline & 20 & & & 0.490 & & & & \\
\hline RGO & 30 & 22.272 & 0.102 & 0.327 & 0.963 & 4.338 & 0.393 & 0.965 \\
\hline & 40 & & & 0.245 & & & & \\
\hline & 50 & & & 0.196 & & & & \\
\hline & 60 & & & 0.163 & & & & \\
\hline & 10 & & & 0.704 & & & & \\
\hline & 20 & & & 0.352 & & & & \\
\hline GEO & 30 & 28.986 & 0.142 & 0.235 & 0.900 & 7.456 & 0.334 & 0.943 \\
\hline GEU & 40 & 28.980 & 0.142 & 0.176 & 0.900 & 1.450 & 0.334 & 0.943 \\
\hline & 50 & & & 0.141 & & & & \\
\hline & 60 & & & 0.117 & & & & \\
\hline
\end{tabular}

The model parameters $\left(K_{F}\right.$ and $\left.1 / n\right)$ can be determined from the linear plot of $\log q_{e}$ versus $\log C_{e}[6,55]$. Figure 7 shows the adsorption isotherms of phenol on CNMs. The isotherms are regular and concave with respect to the concentration axis. According to Giles' classification, these isotherms may be classified as L type for the adsorption of phenol which indicates high affinity of the adsorbent towards the adsorbate and also there is no strong competition from the solvent for adsorption sites.

The isotherm constants and correlation coefficients are shown in Table 3; both the Langmuir and Freundlich isotherm models describe adequately the adsorption data. The magnitude of $1 / n$ quantifies whether the adsorption is favourable and the heterogeneity degree of the CNTs surface. If $1 / n$ is less than unity, it suggests satisfactory adsorption.
Although the equilibrium data fit well both adsorption models, the Freundlich model exhibits slightly better fit to the adsorption data than the Langmuir model. The Freundlich isotherm describes reversible adsorption and is not restricted to the formation of monolayer.

The favorable nature of adsorption can be expressed in terms of an equilibrium parameter $R_{L}$, which is dimensionless, and it is defined as

$$
R_{L}=\frac{1}{\left(1+K_{L} C_{0}\right)}
$$

where $K_{L}$ is the Langmuir constant $(\mathrm{L} / \mathrm{mg})$ and $C_{0}$ is the initial concentration of adsorbate in solution [25].

It is established that (i) $0<R_{L}<1$ for favorable adsorption, (ii) $R_{L}>1$ for unfavorable adsorption, (iii) 


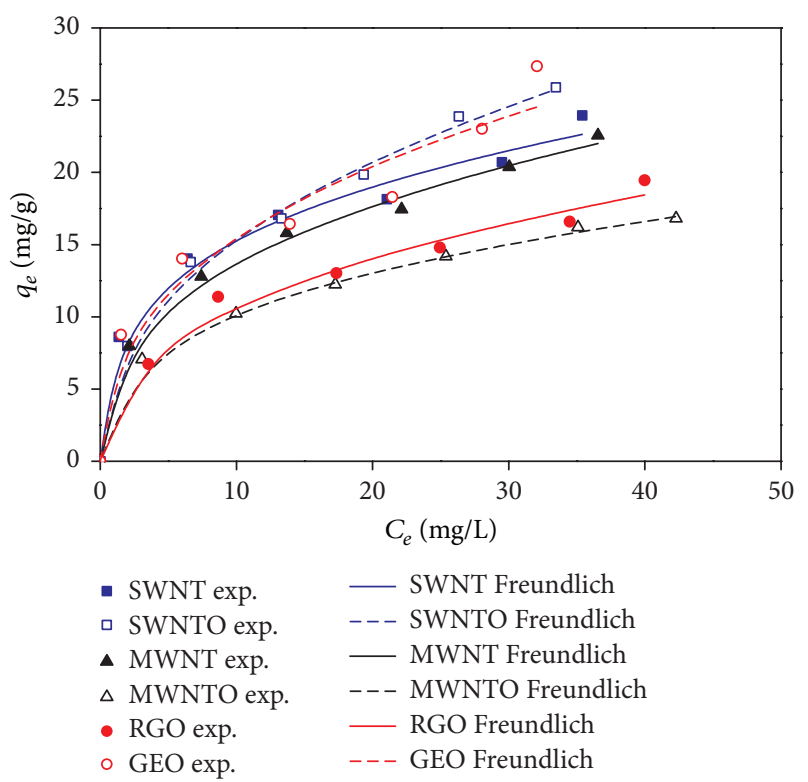

FIgURE 7: Adsorption isotherms of phenol on CNMs $\left(T=25 \pm 2^{\circ} \mathrm{C}\right.$, $\mathrm{pH}=5.0 \pm 0.5$ ).

$R_{L}=1$ for linear adsorption, and (iv) $R_{L}=0$ for irreversible adsorption [31]. The values of $R_{L}$ for all adsorbents are listed in Table 3. $R_{L}$ values obtained are between 0 and 1 , indicating a favourable behavior toward phenol adsorption.

One target of this study is to compare the adsorption capacity with respect to the dimension of the nanomaterial. $1 \mathrm{D}$ and 2D nanomaterials on their unoxidized and oxidized forms are analyzed. This study performs the comparison between MWNT and RGO and MWNTO and GEO since these materials have similar graphitic structures (i.e., MWNT and MWNTO may be considered as rolled up structures of RGO and GEO, resp.). Differences in adsorption capacity between $1 \mathrm{D}$ and $2 \mathrm{D}$ nanomaterials are shown by the adsorption capacity $K_{F}$ obtained from Freundlich model. The parameter, $K_{F}$, decreases in the following order: GEO (7.456) $>\operatorname{MWNT}$ (6.162) > MWNTO (4.777) > RGO (4.338).

Theoretically, RGO exhibits better adsorption capacity than MWNT, because the rolling-up process substantially decreases the number of active sites. However, in this study, $K_{F}$ is smaller on RGO than MWNT. This contradicts the expected results, but it also shows that phenol molecules could be interacting with the active sites inside the MWNT. This is complemented by the fact that intraparticle diffusion model is involved in the adsorption process. Similarly, it can be observed that adsorbate molecules may have difficulty interacting between the stacked graphitic layers of the RGO, due to impurities retained on its surface during synthesis process or by the folding found in these materials. Thus, $1 \mathrm{D}$ nanomaterial in its unoxidized form has greater adsorption capacity than the corresponding $2 \mathrm{D}$ counterpart for the pollutant analyzed in this study.

On the other hand, the GEO has higher adsorption capacity than MWNTO; this indicates that carbon atoms and oxygenated functional groups are available as active sites to interact with phenol molecules on the edge and both sides of the stacked sheets of GEO. In this case, 2D nanomaterial in its oxidized form has greater adsorption capacity than $1 \mathrm{D}$ counterpart. GEO have also presented good capacity to remove other pollutants in water as $\mathrm{Cr}(\mathrm{VI})$, due to the large negatively charged density [56].

It is important to point outthat the nanomaterials with higher adsorption capacity in this comparison (MWNT and GEO) also have greater surface area; this latter is a key factor in the process of adsorption. It is important also to comment that, in this case, the surface area of $1 \mathrm{D}$ and 2D nanomaterials is different between them, because dimension produces different structure features and their synthesis methods of each material are completely different, as mentioned above.

On the other hand, although SWNTs are materials of $1 \mathrm{D}$, the adsorption capacity is higher than MWNT (also 1D materials) and shows the opposite behavior because the oxidized form removes more phenol than pristine material. Thus, SWNTs have a similar behavior to $2 \mathrm{D}$ materials because their oxidized forms remove more phenol than the pristine materials. This effect is attributed to the single walled and the exposed oxygen moieties in the surface, which have more interaction with phenol molecules, and the purification method removes impurities at surface, producing more surface area than the unoxidized form (as it was verified in the SSA results).

\section{Conclusion}

This study confirms that microwave irradiation significantly decreases the time required for oxidation of CNTs. The pseudo-second-order equation provides the best correlation for the adsorption data. The Freundlich adsorption model is more appropriate for describing the adsorption equilibrium data for phenol. The results show that unoxidized form (SWNT and MWNT) 1D nanomaterial has higher adsorption capacity than 2D counterpart. However, oxidized form of 2D nanomaterial presents greater adsorption capacity than $1 D$ counterpart. On the other hand, GEO has greater capacity than RGO, because the free space between the graphitic layers is wider, whereby adsorbate molecules are easier to be adsorbed. The adsorption process occurs mainly by interactions as $\pi-\pi$ and not by electrostatic interactions. The $\pi-\pi$ interactions derive from the interactions between carbonyl groups and $\pi$ electrons that are delocalized in the structure of the graphitic layers and $\pi$ electrons in the aromatic rings of phenol. The $\pi-\pi$ interactions also depend on the contact area between the aromatic molecule of phenol and surface chemistry of carbon nanomaterials. In this study, SWNTO, GEO, and MWNT have high adsorption capacity attributed to their greater surface areas compared to other adsorbents. Hydrogen bonding is another proposed mechanism for the adsorption of phenol on CNMs which may be formed between hydroxyl groups of the adsorbate and hydroxyl, ketone, aldehyde, and carboxylic groups of the adsorbent.

\section{Conflict of Interests}

The authors declare that they have no conflict of interests. 


\section{Acknowledgments}

The authors are grateful to Dr. S. J. Jiménez Sandoval for Raman facilities at CINVESTAV and to Mr. F. Rodríguez Melgarejo for his technical assistance in Raman spectroscopies. They also appreciate the support of Ms. M. L. Palma Tirado for obtaining TEM images. M. de la Luz-Asunción is thankful to CONACYT for Grant no. 47778 and to Universidad Autónoma del Estado de México.

\section{References}

[1] X. Liu, M. Wang, S. Zhang, and B. Pan, "Application potential of carbon nanotubes in water treatment: a review," Journal of Environmental Sciences, vol. 25, no. 7, pp. 1263-1280, 2013.

[2] K. P. Singh, A. Malik, S. Sinha, and P. Ojha, "Liquid-phase adsorption of phenols using activated carbons derived from agricultural waste material," Journal of Hazardous Materials, vol. 150, no. 3, pp. 626-641, 2008.

[3] S.-H. Lin and R.-S. Juang, "Adsorption of phenol and its derivatives from water using synthetic resins and low-cost natural adsorbents: a review," Journal of Environmental Management, vol. 90, no. 3, pp. 1336-1349, 2009.

[4] J. C. Lazo-Cannata, A. Nieto-Márquez, A. Jacoby et al., "Adsorption of phenol and nitrophenols by carbon nanospheres: effect of $\mathrm{pH}$ and ionic strength," Separation and Purification Technology, vol. 80, no. 2, pp. 217-224, 2011.

[5] F. A. Banat, B. Al-Bashir, S. Al-Asheh, and O. Hayajneh, "Adsorption of phenol by bentonite," Environmental Pollution, vol. 107, no. 3, pp. 391-398, 2000.

[6] A. T. Mohd-Din, B. H. Hameed, and A. L. Ahmad, "Batch adsorption of phenol onto physiochemical-activated coconut shell," Journal of Hazardous Materials, vol. 161, no. 2-3, pp. 15221529, 2009.

[7] M. T. Uddin, M. S. Islam, and M. Z. Abedin, "Adsorption of phenol from aqueous solution by water hyacinth ash," Journal of Engineering and Applied Sciences, vol. 2, pp. 11-17, 2007.

[8] L. J. Kennedy, J. J. Vijaya, K. Kayalvizhi, and G. Sekaran, "Adsorption of phenol from aqueous solutions using mesoporous carbon prepared by two-stage process," Chemical Engineering Journal, vol. 132, no. 1-3, pp. 279-287, 2007.

[9] Z. Liu, K. Chen, C. Davis et al., "Drug delivery with carbon nanotubes for in vivo cancer treatment," Cancer Research, vol. 68, no. 16, pp. 6652-6660, 2008.

[10] Z. Liu, X. Sun, N. Nakayama-Ratchford, and H. Dai, "Supramolecular chemistry on water-soluble carbon nanotubes for drug loading and delivery," ACS Nano, vol. 1, no. 1, pp. 50-56, 2007.

[11] B. J. Landi, M. J. Ganter, C. D. Cress, R. A. DiLeo, and R. P. Raffaelle, "Carbon nanotubes for lithium ion batteries," Energy \& Environmental Science, vol. 2, no. 6, pp. 638-654, 2009.

[12] H. Karimi-Maleh, P. Biparva, and M. Hatami, "A novel modified carbon paste electrode based on $\mathrm{NiO} / \mathrm{CNTs}$ nanocomposite and (9, 10-dihydro-9, 10-ethanoanthracene-11, 12-dicarboximido)4-ethylbenzene-1, 2-diol as a mediator for simultaneous determination of cysteamine, nicotinamide adenine dinucleotide and folic acid," Biosensors and Bioelectronics, vol. 48, pp. 270275,2013
[13] H. Karimi-Maleh, F. Tahernejad-Javazmi, A. A. Ensafi, R. Moradi, S. Mallakpour, and H. Beitollahi, "A high sensitive biosensor based on FePt/CNTs nanocomposite/N-(4hydroxyphenyl)-3,5-dinitrobenzamide modified carbon paste electrode for simultaneous determination of glutathione and piroxicam," Biosensors and Bioelectronics, vol. 60, pp. 1-7, 2014.

[14] Z. Liu, X. Lin, J. Y. Lee, W. Zhang, M. Han, and L. M. Gan, "Preparation and characterization of platinum-based electrocatalysts on multiwalled carbon nanotubes for proton exchange membrane fuel cells," Langmuir, vol. 18, no. 10, pp. 4054-4060, 2002.

[15] S. Saito, "Carbon nanotubes for next-generation electronics devices," Science, vol. 278, no. 5335, pp. 77-78, 1997.

[16] C. Liu, Y. Chen, C.-Z. Wu, S.-T. Xu, and H.-M. Cheng, "Hydrogen storage in carbon nanotubes revisited," Carbon, vol. 48, no. 2, pp. 452-455, 2010.

[17] P. E. Diaz-Flores, F. López-Urías, M. Terrones, and J. R. RangelMendez, "Simultaneous adsorption of $\mathrm{Cd}^{2+}$ and phenol on modified N-doped carbon nanotubes: experimental and DFT studies," Journal of Colloid and Interface Science, vol. 334, no. 2, pp. 124-131, 2009.

[18] X. Ren, C. Chen, M. Nagatsu, and X. Wang, "Carbon nanotubes as adsorbents in environmental pollution management: a review," Chemical Engineering Journal, vol. 170, no. 2-3, pp. 395-410, 2011.

[19] K. A. Mkhoyan, A. W. Contryman, J. Silcox et al., "Atomic and electronic structure of graphene-oxide," Nano Letters, vol. 9, no. 3, pp. 1058-1063, 2009.

[20] D. Zhang, X. Liu, and X. Wang, "Green synthesis of graphene oxide sheets decorated by silver nanoprisms and their antibacterial properties," Journal of Inorganic Biochemistry, vol. 105, no. 9, pp. 1181-1186, 2011.

[21] H.-L. Guo, X.-F. Wang, Q.-Y. Qian, F.-B. Wang, and X.-H. Xia, "A green approach to the synthesis of graphene nanosheets," ACS Nano, vol. 3, no. 9, pp. 2653-2659, 2009.

[22] K. Zhang, V. Dwivedi, C. Chi, and J. Wu, "Graphene oxide/ferric hydroxide composites for efficient arsenate removal from drinking water," Journal of Hazardous Materials, vol. 182, no. 1-3, pp. 162-168, 2010.

[23] P. Khanra, T. Kuila, N. H. Kim, S. H. Bae, D.-S. Yu, and J. H. Lee, "Simultaneous bio-functionalization and reduction of graphene oxide by baker's yeast," Chemical Engineering Journal, vol. 183, pp. 526-533, 2012.

[24] M. Iliut, C. Leordean, and V. Canpean, "A new green, ascorbic acid-assisted method for versatile synthesis of Au-graphene hybrids as efficient surface-enhanced Raman scattering platforms," Journal of Materials Chemistry C, vol. 1, no. 26, pp. 40944104, 2013.

[25] R. Arasteh, M. Masoumi, A. M. Rashidi, L. Moradi, V. Samimi, and S. T. Mostafavi, "Adsorption of 2-nitrophenol by multiwall carbon nanotubes from aqueous solutions," Applied Surface Science, vol. 256, no. 14, pp. 4447-4455, 2010.

[26] A. Pacholczyk, A. P. Terzyk, M. Wiśniewski et al., "Phenol adsorption on closed carbon nanotubes," Journal of Colloid and Interface Science, vol. 361, no. 1, pp. 288-292, 2011.

[27] C.-C. Chen, X.-Q. Shan, Y.-S. Wang et al., "Adsorption of 2,4,6trichlorophenol by multi-walled carbon nanotubes as affected by Cu(II)," Water Research, vol. 43, no. 9, pp. 2409-2418, 2009. 
[28] M. Wiśniewski, A. P. Terzyk, P. A. Gauden, K. Kaneko, and Y. Hattori, "Removal of internal caps during hydrothermal treatment of bamboo-like carbon nanotubes and application of tubes in phenol adsorption," Journal of Colloid and Interface Science, vol. 381, no. 1, pp. 36-42, 2012.

[29] A. Tóth, A. Törocsik, E. Tombácz, and K. László, “Competitive adsorption of phenol and 3-chlorophenol on purified MWCNTs," Journal of Colloid and Interface Science, vol. 387, no. 1, pp. 244-249, 2012.

[30] Q. Liao, J. Sun, and L. Gao, "Adsorption of chlorophenols by multi-walled carbon nanotubes treated with $\mathrm{HNO}_{3}$ and $\mathrm{NH}_{3}$," Carbon, vol. 46, no. 3, pp. 553-555, 2008.

[31] C.-Y. Kuo, "Comparison with as-grown and microwave modified carbon nanotubes to removal aqueous bisphenol A," Desalination, vol. 249, no. 3, pp. 976-982, 2009.

[32] Y. Li, Q. Du, T. Liu et al., "Equilibrium, kinetic and thermodynamic studies on the adsorption of phenol onto graphene," Materials Research Bulletin, vol. 47, no. 8, pp. 1898-1904, 2012.

[33] J. Xu, L. Wang, and Y. Zhu, "Decontamination of bisphenol A from aqueous solution by graphene adsorption," Langmuir, vol. 28, no. 22, pp. 8418-8425, 2012.

[34] Y. Zhang, Y. Cheng, N. Chen et al., "Recyclable removal of bisphenol A from aqueous solution by reduced graphene oxidemagnetic nanoparticles: adsorption and desorption," Journal of Colloid and Interface Science, vol. 421, pp. 85-92, 2014.

[35] X. Wang, S. Huang, L. Zhu, X. Tian, S. Li, and H. Tang, "Correlation between the adsorption ability and reduction degree of graphene oxide and tuning of adsorption of phenolic compounds," Carbon, vol. 69, pp. 101-112, 2014.

[36] J. Xu and Y.-F. Zhu, "Elimination of bisphenol A from water via graphene oxide adsorption," Acta Physico-Chimica Sinica, vol. 29, no. 4, pp. 829-836, 2013.

[37] N. Remya and J.-G. Lin, "Current status of microwave application in wastewater treatment-a review," Chemical Engineering Journal, vol. 166, no. 3, pp. 797-813, 2011.

[38] J. Shen, T. Li, and Y. Long, "One-step solid state preparation of reduced graphene oxide," Carbon, vol. 7033, pp. 1-23, 2012.

[39] M. Zhang, S. Liu, X. M. Yin et al., "Fast synthesis of graphene sheets with good thermal stability by microwave irradiation," Chemistry-An Asian Journal, vol. 6, no. 5, pp. 1151-1154, 2011.

[40] W. S. Hummers Jr. and R. E. Offeman, "Preparation of graphitic oxide," Journal of the American Chemical Society, vol. 80, no. 6, p. 1339, 1958.

[41] J. Zhang, H. Yang, G. Shen, P. Cheng, J. Zhang, and S. Guo, "Reduction of graphene oxide vial-ascorbic acid," Chemical Communications, vol. 46, no. 7, pp. 1112-1114, 2010.

[42] T. Mahmood, M. T. Saddique, A. Naeem, P. Westerhoff, S. Mustafa, and A. Alum, "Comparison of different methods for the point of zero charge determination of $\mathrm{NiO}$," Industrial \& Engineering Chemistry Research, vol. 50, no. 17, pp. 10017-10023, 2011.

[43] Q.-S. Liu, T. Zheng, P. Wang, J.-P. Jiang, and N. Li, "Adsorption isotherm, kinetic and mechanism studies of some substituted phenols on activated carbon fibers," Chemical Engineering Journal, vol. 157, no. 2-3, pp. 348-356, 2010.

[44] V. Datsyuk, M. Kalyva, K. Papagelis et al., "Chemical oxidation of multiwalled carbon nanotubes," Carbon, vol. 46, no. 6, pp. 833-840, 2008.
[45] S. Yin, P. K. Shen, S. Song, and S. P. Jiang, "Functionalization of carbon nanotubes by an effective intermittent microwave heating-assisted $\mathrm{HF} / \mathrm{H}_{2} \mathrm{O}_{2}$ treatment for electrocatalyst support of fuel cells," Electrochimica Acta, vol. 54, no. 27, pp. 6954-6958, 2009.

[46] J. Liu, M. R. I. Zubiri, B. Vigolo et al., "Efficient microwaveassisted radical functionalization of single-wall carbon nanotubes," Carbon, vol. 45, no. 4, pp. 885-891, 2007.

[47] C.-J. Kim, W. Khan, and S.-Y. Park, "Structural evolution of graphite oxide during heat treatment," Chemical Physics Letters, vol. 511, no. 1-3, pp. 110-115, 2011.

[48] E. Jimenez-Cervantes Amieva, R. Fuentes-Ramirez, A. L. Martínez-Hernández et al., "Graphene oxide and reduced graphene oxide modification with polypeptide chains from chicken feather keratin," Journal of Alloys and Compounds, vol. 643, supplement 1, pp. S137-S143, 2015.

[49] Y. Peng and H. Liu, "Effects of oxidation by hydrogen peroxide on the structures of multiwalled carbon nanotubes," Industrial \& Engineering Chemistry Research, vol. 45, no. 19, pp. 64836488, 2006.

[50] K. Chajara, C.-H. Andersson, J. Lu, E. Widenkvist, and H. Grennberg, "The reagent-free, microwave-assisted purification of carbon nanotubes," New Journal of Chemistry, vol. 34, no. 10, pp. 2275-2280, 2010.

[51] Y.-C. Ling and A. Deokar, "Microwave-assisted preparation of carbon nanotubes with versatile functionality," in Carbon Nanotubes Applications on Electron Devices, J. M. Marulanda, Ed., chapter 5, pp. 127-142, InTech, Rijeka, Croatia, 2011.

[52] A. Y. Dursun and Ç. S. Kalayci, "Equilibrium, kinetic and thermodynamic studies on the adsorption of phenol onto chitin," Journal of Hazardous Materials, vol. 123, no. 1-3, pp. 151157, 2005.

[53] G. Zhao, J. Li, and X. Wang, "Kinetic and thermodynamic study of 1-naphthol adsorption from aqueous solution to sulfonated graphene nanosheets," Chemical Engineering Journal, vol. 173, no. 1, pp. 185-190, 2011.

[54] N. Calace, E. Nardi, B. M. Petronio, and M. Pietroletti, "Adsorption of phenols by papermill sludges," Environmental Pollution, vol. 118, no. 3, pp. 315-319, 2002.

[55] J.-M. Li, X.-G. Meng, C.-W. Hu, and J. Du, "Adsorption of phenol, p-chlorophenol and p-nitrophenol onto functional chitosan," Bioresource Technology, vol. 100, no. 3, pp. 1168-1173, 2009.

[56] E. K. Goharshadi and M. B. Moghaddam, "Adsorption of hexavalent chromium ions from aqueous solution by graphene nanosheets: kinetic and thermodynamic studies," International Journal of Environmental Science and Technology, vol. 12, no. 7, pp. 2153-2160, 2015. 

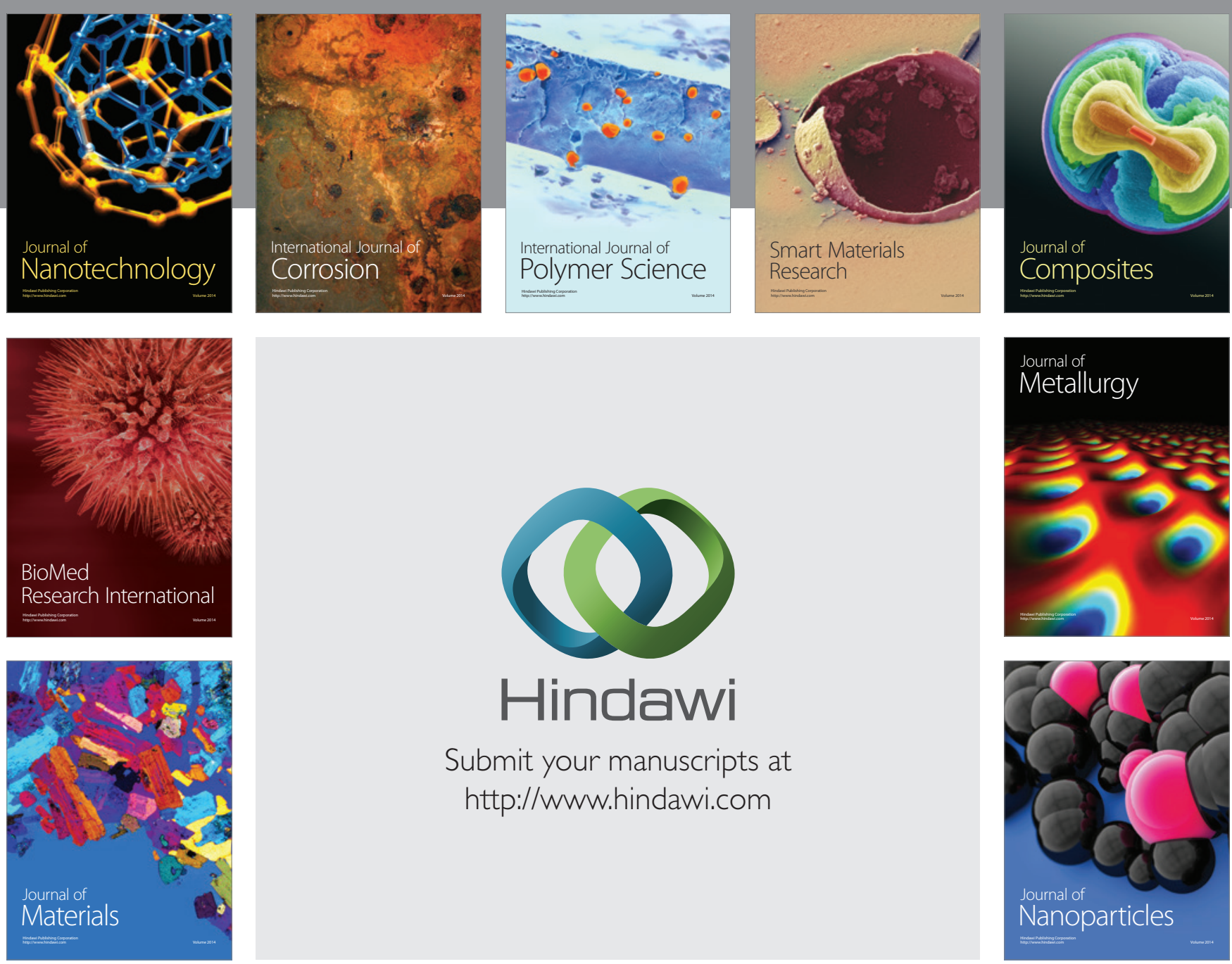

Submit your manuscripts at http://www.hindawi.com
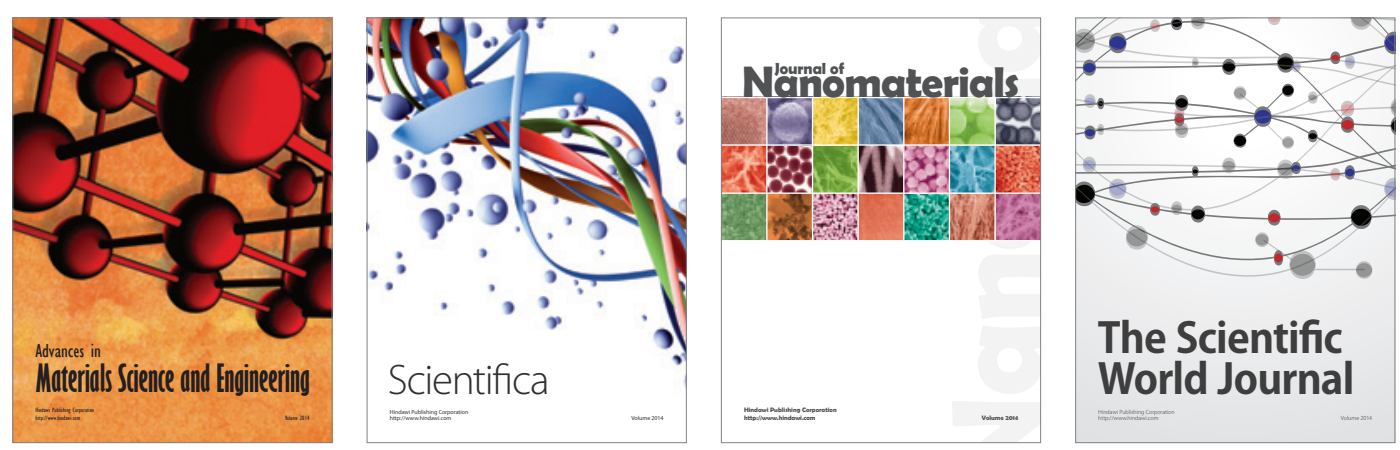

\section{The Scientific World Journal}
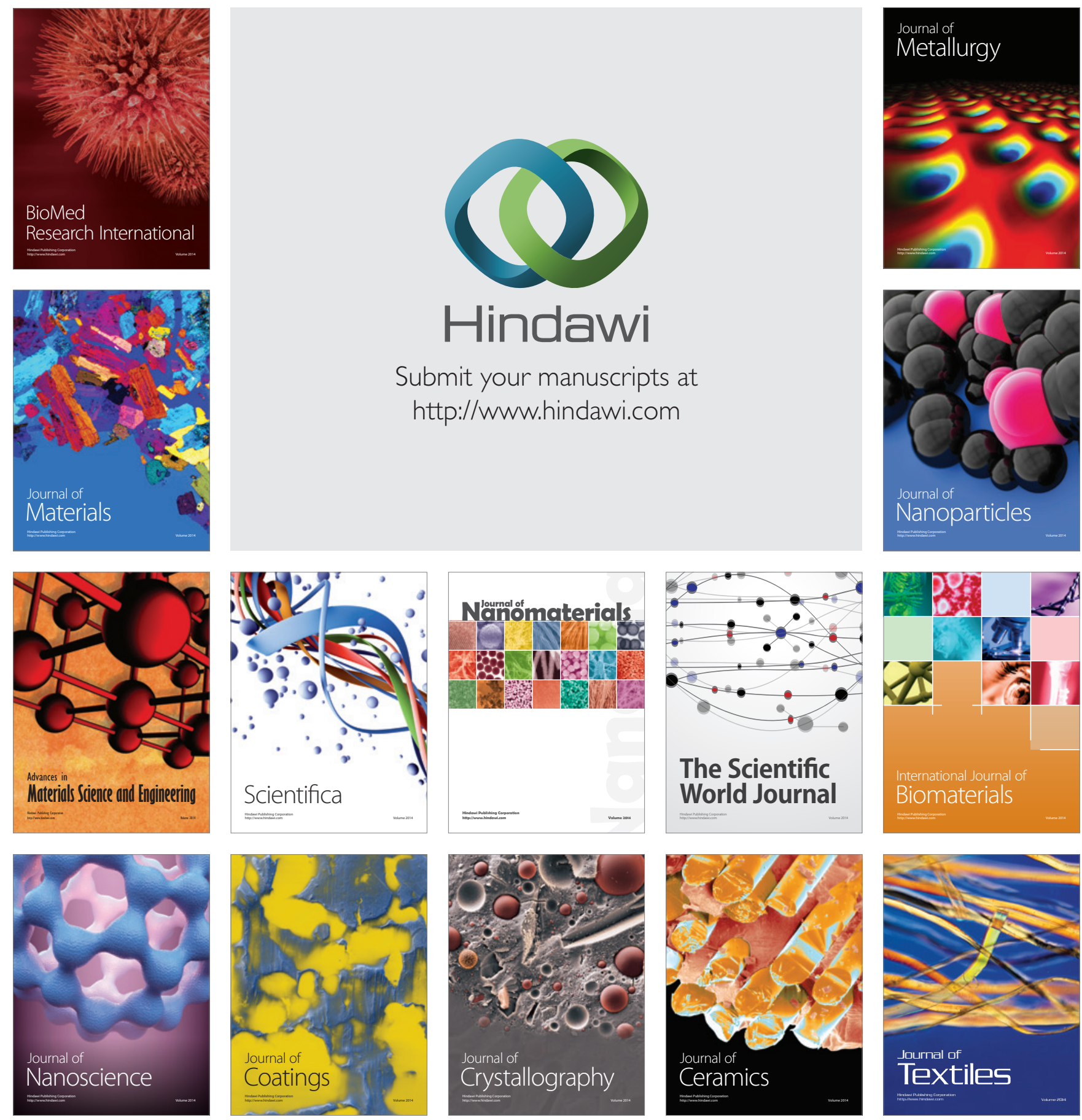